\title{
From Citation to Piece in Hand: The Search for Efficiency in Accessing Monographic Series
}

\section{Marian Shemberg}

The author of this article looks at access problems that occur when the citations from indexes for articles in series differ from the way the items are cataloged. To illustrate the difficulties encountered, a search was conducted in the online catalogs of various libraries and a comparison made between the bibliographic entries found to citations both in electronic indexes and in authors' references. The results indicate that the ramifications of local cataloging decisions affect all areas of librarianship. In this electronic age, the need is great to integrate the various sources of information needed for a patron to go from citation to piece in hand.

B to Periodicals in 1848, libraries, of sheer necessity, have outsourced indexing of articles in journals to producers of databases. Tyckoson $(1989,10)$ states that "the failure of the catalog to incorporate the growing number of journals and other special formats has resulted in an entire industry of commercial services designed to supplement the catalog in this area." Yet until recently, the catalog was not designed to assist the patron in the transition from an indexing citation to the bibliographic record in order to locate and retrieve the desired item. There has been limited standardization or coordination between the abstracting and library worlds.

The use of the catalog as a finding aid was addressed by Tate (1963), who compared main entries in the Library of Congress (LC) card catalog with citations in references. Relevant to the present study, Tate $(\$ 190)$ also compared the citations "with the corresponding catalog entries for data regarding useful secondary entries." Though only peripheral to her study, she (p.191) did point out that one type of "secondary entry that may have some utility as a finding device is the series entry." Tate also warned that secondary entries vary over time and among libraries, with the needs of the individual library taking precedence over standardization. Even at that time, she mentioned the problems of growth of the catalog and the expense to libraries in adding secondary entries. It appears that more than thirty years later, libraries are still grappling with these issues.

Only one other article (Tagliacozzo, Rosenberg, and Kochen 1970) was found in which the researchers examined the information that patrons brought to the catalog in searching for known items. They did not focus on series but rather directed their attention toward the search

Marian Shemberg (shemberg.3@osu.edu) is Reference/Automation Librarian, Education/Psychology Library, Ohio State University. Manuscript received January 16, 1997; accepted for publication March 14, 1997. 
process and patrons' ability to find the item sought. They state (p. 231): "the catalogue has to contain at least one written record representing the item ... that the user is trying to find; the user has to find one such record; and he has to recognize it as corresponding to his mental representation of the object of his search." It is this last aspect that is examined in the present research.

The difficulties that patrons face when they go from known-item series entries to the catalog is an area in which little has been written. No further research studies were found that related bibliographic citations of series to finding these items in the catalog. In this article, I review access problems that face the catalog user as a result of differences in the way an item in a series is represented in various forms in indexes and in the catalog.

It is acknowledged that cataloging monographic series is complex. Authors have raised this topic in the cataloging literature as an ongoing issue. Steinhagen (1989) enumerates some of the complicated issues with which catalogers have struggled cataloging serials and series. McBride (1985) gives a history of the attempts to deal with monographic series.

However, catalogers are not the only ones struggling with this issue. Representation of an item in the catalog, especially a serial or series, not only affects the patron; it affects all areas of librarianship. In this article, I review the issue from the perspective of the reference librarian and try to identify some options to meet the different needs of publishers, indexers, and librarians in light of the state of technology today.

\section{THE Issues}

To illustrate the problems of access that a user might encounter in moving from a citation to a piece in hand, we will look at a specific series that has kept the same title, the same ISSN, and the same editors since 1973, yet is still elusive to identify. The title of this series is New Directions for Community Colleges (NDCC), a series published by Jossey-Bass that is important in the field of education and is used heavily at Ohio State University (OSU). With continuity of title, ISSN, series editors, and place of publication, one would think it would be easy to identify individual pieces. However, reference librarians at the Education/Psychology Library at OSU have been aware of problems in accessing this series for years. It is especially troublesome because of its double numbering system, and because at OSU it had been cataloged as an unanalyzed serial until 1989. At that time, the cataloging treatment was changed to individual monographic records, to provide better access.

It seems reasonable to posit that access is facilitated if an item is cataloged in the same way in which it is indexed in databases and used in references or bibliographies. This hypothesis is based on the ideas of standardization and consistency. Crawford (1987 and 1992) emphasizes that a catalog should be clear and consistent. He states $(1987,68)$ that "usage should be consistent from a patron's view, not from a designer's view." Consistency is also beneficial when moving from an electronic index to the online catalog. Snavely and Clark $(1996,50)$ point out that the "process, from having the citation in hand to having the article in hand, has been largely overlooked in the literature." Awareness of problems in retrieving items from citations is a first step to improving success in retrieval.

Problems in identifying the example series center around the following factors:

1. Inconsistency in cataloging treatments due to human error

2. Dual numbering systems on the source

3. Local decisions over time and in multiple branch libraries to catalog item as a serial, a monograph in a series, or both

4. Whether or not the field containing the series entry is indexed

5. Citation differences in electronic indexes

6. Ways in which articles are cited in references

7. Screen display

Although these factors refer to one title in a specific library, the same factors 
can be found in part in any larger library, especially those with large serial holdings.

\section{METHODOLOGY}

Each issue of NDCC, beginning with number 1 (1973), was examined for citation information, numbering systems, and changes in description on the title page and its verso.

The online catalog at OSU (OSCAR) was checked to see how each issue was handled over time. OSU belongs to the OhioLINK consortium, which is a statewide consortium linking academic, community college, and research libraries in the state of Ohio. OhioLINK's computerized union catalog is accessible through the Internet. The title was also searched in the central OhioLINK catalog and individually in the catalogs of member libraries. When there were gaps in issue holdings at member institutions, each catalog was checked by individual issue title to determine whether the item was owned but either not identified or not indexed by series title. Of the 30 libraries in the system at the time of this writing, 17 libraries had at least 10 issues of NDCC.

When it was discovered that cataloging practices of member libraries varied greatly, catalog records for this title were also examined at large research libraries outside the consortium via a Z39.50 interface to see whether large research institutions cataloged these items at a more consistent level.

The libraries that were searched included LC and four members of the Association of Research Libraries (ARL) outside the state of Ohio. When the Z39.50 search interface being used to access other catalogs proved too restrictive at $\mathrm{LC}$ and one ARL library, those catalogs were searched directly via the Internet using the remote catalogs native software. These methods were used to identify consistency and differences in cataloging practices of the sample of large research libraries. Then comparisons were made across all catalogs on the treatment of this series.

Many patrons get citations to articles in the NDCC by way of electronic indexes. So the form of citation in several elec- tronic databases that index this series were searched by series title to determine the form of the citations found there. The indexes used were ERIC, Education Index, ArticleFirst, and CARL UnCover. Particular attention was paid to how the citations meshed with bibliographic records in the various online catalogs.

Another patron source for NDCC citations is bibliographic references in the education literature. This was examined through a Dialog search of Social Sciences Citation Index (SSCI). The first search of SSCI was for the series title using "New Directions Community" as the search terms; 120 references to NDCC were found for which copies of the actual articles could be obtained. Because the series title was used to retrieve the references, it seems logical that all 120 matches contained the series title in the citation. This was true, with some variations that could also affect retrieval in a local catalog: 109 had the correct title; 10 had New Directions in Community Colleges instead of "for," and one left off the final $s$ from "Colleges."

Finally, multiple access points were compared among the databases-the citations in references and the various catalogs. These included series title, issue title, sequential number, volume and issue numbers, ISSN, and dates. The time period of the study was September 1995 through June 1996.

\section{Findings}

\section{HOW THE PUblisher IDENTIFIES THESE ITEMS}

NDCC has been published quarterly since 1973. Each issue is identified both by a sequential number and by volume and issue numbers. Each issue also has a unique title in addition to the series title, as well as issue editors and series editors. From its inception in 1973 until mid1981, each of these issues had two separate title pages. The first is the series title page, which includes the editors of the series, the sequential number, and the date. The second title page gives only the unique issue title, the editors of that 
theme issue, and the publisher. Additionally, the verso of the second title page lists a volume number in roman numerals and an issue number, different from the sequential numbering of the series. The sequential number is not repeated on the verso from 1973 to 1982 . In 1983, the sequential number was added to the verso of the title page. Also, ongoing from issue number 5 (1974) through number 68 (1989), a supplementary note on the verso of the title page states, "New Directions is numbered sequentially. . . . The volume and issue numbers above are included for the convenience of libraries" (NDCC 1974, title page verso).

The date designations on the issues of NDCC also vary. Issues number 1 , spring 1973, through number 22, summer 1978, have dates of spring, summer, autumn, or winter, plus the year. Then only the year is indicated on the title page until issue number 35 , where the date changes to the month and year, e.g., September 1981. Each issue then gives a month and year through issue number 54, June 1986. From issue number 55 to the present, the dates are fall, winter, spring, or summer and the year. Again, although these variations refer specifically to $N D C C$, any public or technical service librarian (and some sophisticated patrons) know this problem is by no means unique.

\section{BIBLIOGRAPHIC RECORDS IN Online Catalogs}

Various libraries have cataloged this title as an unanalyzed serial, as an analyzed serial, or as a monograph in a series, both with series entries indexed and not indexed. LC's series authority record for the series indicates that it is considered a monographic series (MARC field 646) for issues $1-45$ and a serial for number 46 on. For dates of publication and volume designations, the record shows number 1 (spring 1973). Therefore, from 1973 to 1984 , issues number 1 through number 45, LC separately cataloged this title as a monograph with a series entry. A MARC 515 note (numbering peculiarities) states that issues from number 46 are also called volume 12 , number 2 , and so on. All of the issues have volume and issue numbers in roman numerals on the verso of the title page, yet the authority record indicates only that a dual numbering system is used from number 46 , which is when LC started cataloging NDCC as a serial. Therefore, patrons checking LOCIS, the online catalog at LC, will find separate records for each of the first 45 issues in the monographs catalog, but will find one serial record in the serial catalog by series title only. As Hagler and Simmons (1982, 105) state, "It should be no surprise that the policies of the Library of Congress, like those of any other library, change from time to time." Most information in a bibliographic record is taken from the item itself; in the case of this 515 note, it appears to indicate local practice treatment (monograph series versus serial), not the history of the item.

In monographic records of this title, librarians have either used the sequential number, the volume and issue numbers, or a combination of the two. One way librarians identify the dual numbering system is to trace by one number but to indicate in a series field or a note field an alternate numbering system. For example, number 37 is identified as "number $37=v 10$, number 1 (Mar. 1982)." This redundancy is a great service to patrons and public service librarians alike, who might bring only partial information to the cata$\log$. The note information might not be an access point in all catalogs; however, it may ease identification of a particular issue once the bibliographic record is retrieved.

Another way that librarians identify the dual numbering systems is with notes indicating that the series is also numbered by a certain volume and issue on the verso of the title page. Occasionally, due to errors, the identifying issue numbers are omitted. This makes access and identification extremely difficult for the patron.

The addition of the Blackwell North America Table of Contents service at OhioLINK has improved identification and retrieval of NDCC articles. Many monographic records in this series include notes or contents that identify chapter titles and chapter authors. These addi- 
TABLE 1

Cataloging Practices of Ohiolink Libraries for NDCC

\begin{tabular}{lccccc}
\hline $\begin{array}{l}\text { Number of } \\
\text { Libraties }\end{array}$ & $\begin{array}{c}\text { Cataloged as } \\
\text { Serial }\end{array}$ & $\begin{array}{c}\text { Cataloged as } \\
\text { Mono in Series }\end{array}$ & $\begin{array}{c}\text { Cataloged Both as } \\
\text { Mono and Serial }\end{array}$ & $\begin{array}{c}\text { Volume/Issue } \\
\text { Number Traced }\end{array}$ & $\begin{array}{c}\text { Sequential } \\
\text { Number Traced }\end{array}$ \\
\hline 7 & $\mathrm{X}$ & & $\mathrm{X}$ & $\mathrm{X}$ \\
4 & $\mathrm{X}$ & & & $\mathrm{X}$ \\
4 & & $\mathrm{X}$ & & $\mathrm{X}$ \\
1 & & $\mathrm{X}$ & $\mathrm{X}$ & $\mathrm{X}$ \\
1 & & $\mathrm{X}$ (analyzed) & $\mathrm{X}$ & $\mathrm{X}$
\end{tabular}

tions to the records are retrievable by keyword search and by title or author if "Table of Contents" is a feature of the search interface. Such additions help enormously in creating an efficient and effective system for accessing this type of publication.

\section{BIBLIOGRAPHIC RECORDS IN A UNION Catalog}

All member libraries of OhioLINK use the Innovative Interfaces system (INNOPAC). Patrons can access the central union catalog or any of the individual member catalogs through the Internet.

The central union catalog has 97 titles cataloged under NDCC. All are monographs in a series except for one serial record. The screen displays make identification of the serial record difficult. Cataloging an item as part of a serial makes "one record that will stand for all the individual issues of a serial title, with little ongoing maintenance" (Intner 1990, 4). Cataloging series as an unanalyzed serial is convenient for processing purposes, but users might need greater expertise to recognize a serial record and interpret issue holdings attached to the record. In OhioLINK, full bibliographic records retrieved for the monographic entries have a unique issue title and issue editor. Each title is identified as part of the series. In the central union catalog, the series field indicates the sequential number. Most records do not identify the volume and issue number. Some records, as in the LC records referred to above, show both the sequential number and the volume and issue numbers, but the series is indexed by the sequential number. If the local system sorts numbered issues separately from volumes, an added complication for patrons is introduced. Table 1 provides a summary of citations to $N D C C$ retrieved from OhioLINK libraries.

\section{Searching Other Online Catalogs}

LC and four ARL libraries were also searched. However, access to catalog information via a Z39.50 interface can vary. Holdings, in most cases, were not indicated, which prevents identification of items in a serial record.

The first ARL library was searched by series title. The first record retrieved was the serial authority record. In a 515 field is the note "Volume numbering ceased with the December 1982 issue." This seems in conflict with the 515 note from LC, which indicates that, from number 46 , items are also called volume 12 , number 2 , and so on. This note reflects local information, not what indexes may cite as being on the actual item. Up through number 40 , some records are identified by the sequential number, while others are identified by volume and issue numbers. Starting with number 41 (1983), the rest of the monograph records use the sequential number. The second and third libraries treat this series both as a serial and as a monograph with a series added entry. This dual treatment occurs because one branch or departmental library may cata$\log$ the series as monographic, while another catalogs it as a serial. One might be analyzed, while another might not.

Searching the last library via Z39.50 
TABLE 2

How LC and ARL Libraries Catalog This Series

\begin{tabular}{lcccc}
\hline Library & $\begin{array}{c}\text { Cataloged both as } \\
\text { Mono and Serial }\end{array}$ & $\begin{array}{c}\text { Cataloged as } \\
\text { Mono in Series }\end{array}$ & $\begin{array}{c}\text { Traced by } \\
\text { Sequential Number }\end{array}$ & $\begin{array}{c}\text { Traced by } \\
\text { Volume/Issue } \\
\text { Number }\end{array}$ \\
\hline LC & $\mathrm{X}$ & $\mathrm{X}$ & $\mathrm{v} 1 \mathrm{n} 1$ \\
Library A & $\mathrm{X}$ (analyzed) & $\mathrm{X}$ & $\mathrm{X}$ \\
Library B & $\mathrm{X}$ & $\mathrm{X}$ & $\mathrm{v} \ln 1$ \\
Library C & $\mathrm{X}$ (analyzed & $\mathrm{X}$ & \\
Library D & $\mathrm{X}$ (analyzed) & $\mathrm{X}$ & $\mathrm{v} \ln 1$ \\
\hline
\end{tabular}

was not as successful. Three serial records were located, but no monographic records were retrieved when searching by series title. A search by each issue title was then performed. This search yielded all issues of the series. It was found that the remote search interface provided for a search by series, separate from a title search. This search produced the monographic records. In this library's catalog, the series cannot be searched as a title, and the Z39.50 interface does not have a series search option.

At LC, the Z39.50 search interface allowed for searches only of the book catalog. The first 45 issues were retrieved. To find the serial record at LC, LOCIS was accessed through the Internet. A summary of the category treatment by LC and the ARL libraries is shown in table 2.

\section{RESULTS}

What becomes clear after searching all of these catalogs is that standards vary or are unclear, especially to the remote user. Local practice determines how this series will be cataloged. One branch of a library might catalog it as a serial and another as a monograph; one might index with the volume and issue numbers, another might index by the sequential number. Two or three records for different copies of the same issue might be present in the cata$\log$. Few libraries used one bibliographic record and attached all holdings to that one record. This proved to be a major impediment to access and retrieval, an impediment that has significance for ref- erence, interlibrary loan, acquisitions, cataloging, and binding. Consistency and compromise are needed in cataloging centers at each university or research center.

It would be simpler if there were a national policy on series identification and citation that was followed by publishers, abstractors, and libraries. LC has provided much guidance in the past. Yet Hagler and Simmons (1982, 105) point out that, "the policies of the Library of Congress concerning such matters as series cataloguing, the provision of analytics and contents notes, etc., are those best suited to its own particular needs as a large research library." However, most libraries use shared catalog records often derived from LC copy.

\section{MONOGRAPHIC TREATMENT}

A number of observations can be made with regard to monographic treatment of this series.

- OhioLINK member libraries, LC, and one ARL library that catalog this series as a monograph (or the monograph records of the analyzed serial) display the records in sequential number order.

- The other ARL libraries that catalog this series as a monograph (or as an analyzed serial) display the monographic records in alphabetical order by unique issue title or main entry. Some records appear in the multiple title list by series title, some by issue title, and one appears by the editor of the issue, depending on the main entry. This arrangement has two draw- 
TABLE 3

How NDCC Is CiTED IN INDEXES

\begin{tabular}{lccccc}
\hline Index & $\begin{array}{c}\text { Series Title } \\
\text { Shown }\end{array}$ & $\begin{array}{c}\text { Issue Title } \\
\text { Shown }\end{array}$ & $\begin{array}{c}\text { Sequential Nos. } \\
\text { Shown }\end{array}$ & $\begin{array}{c}\text { Volume/tsue } \\
\text { Nos. Shown }\end{array}$ & $\begin{array}{c}\text { Issue Editor(s) } \\
\text { Shown }\end{array}$ \\
\hline ERIC journals & $\mathrm{X}$ & & $81,82,84,85$ & $\mathrm{X}$ & \\
$\begin{array}{l}\text { ERIC Fiche } \\
\text { Issues }\end{array}$ & $\mathrm{X}$ & $\mathrm{X}$ & $\begin{array}{c}\text { With } \\
\text { exceptions }\end{array}$ & $\mathrm{X}$ & $\mathrm{X}$ \\
$\begin{array}{l}\text { Education } \\
\text { Index articles }\end{array}$ & $\mathrm{X}$ & $\mathrm{X}$ & $\mathrm{X}$ & & \\
$\begin{array}{l}\text { Education } \\
\text { Index issues }\end{array}$ & $\mathrm{X}$ & $\mathrm{X}$ & $\mathrm{X}$ & & $\mathrm{X}$ \\
$\begin{array}{l}\text { ArticleFirst } \\
\text { CARL }\end{array}$ & $\mathrm{X}$ & Some issues & $\mathrm{X}$ & Volume only & \\
$\quad$ UnCover & $\mathrm{X}$ & & $\mathrm{X}$ & & \\
\hline
\end{tabular}

backs. One is that the issue titles are typically not present in records of the electronic indexing services. The second is that the sequential number and volume number may not be displayed in the local catalog's multiple title screen.

- In addition to inconsistencies among catalogs, some show internal variations. Monographs are sometimes indexed with the sequential number and other times with the volume and issue numbers in the same library. At times, these "missing" items are owned but are cataloged by volume and issue numbers, so are located further down in the multiple display screen. Other times they are not owned. It is difficult for the patron to determine which is the case.

- Records of some issues are not indexed by the series, though they may have a series statement. They are not retrieved by series title.

- Errors occur. For example, issue number 2 at one library has two separate item records attached to it. One is the correct issue number 2 (1973) Meeting the Financial Crisis. The other is number 34 (volume 9, no. 2), Women in Community Colleges. There is no separate title entry for issue number 34 for that library.

- The number of the issue is not indicated. By searching for these monographs by known issue title, the sequential number was ascertained.

\section{Serial Treatment}

A number of observations can be made with regard to serial treatment of this series.

- Some holdings in the serial records are identified by volumes while others are shown as numbers. Often the sequential number is incorrectly identified by the volume label. At times, no identifying number is included.

- A serial record may exist, but only one issue is listed as a holding. The rest of the issues are cataloged as monographs. Or isolated issues are cataloged as monographs, while the rest of the collection is cataloged as a serial.

- Libraries catalog these items both as a serial and as monographs in a series. Sometimes the same issues are cataloged in two separate ways by different catalog centers at the same institution. Dual cataloging may be helpful to patrons or may be confusing.

Consistency is a feature that patrons assume about an online catalog, and when that consistency fails to materialize, patrons are poorly served. However, citations may also add to patron confusion.

\section{CITATIONS FROM INDEXES}

Various indexes treat this title differently. Each treatment is described below; an outline is provided in table 3 .

ERIC. ERIC has the longest history of citing NDCC, having cited it continuously 
TABLE 4

SSCI SERIES TITLE SEARCH

\begin{tabular}{lrc}
\hline \hline N=120 & No. & $\%$ \\
\hline Series title cited & 120 & 100.0 \\
Issue title cited & 74 & 68.0 \\
Sequential number cited & 91 & 76.0 \\
Volume number cited & 24 & 20.0 \\
Issue number with volume & 9 & 7.5 \\
\hline
\end{tabular}

since 1973. Until 1983, it was the only service indexing this series. ERIC citations to NDCC are consistent over timethey include the chapter author and chapter title, series title, volume and issue numbers, and date. When the ERIC microfiche format of whole issues of this series is cited, the sequential number is usually added to the title entry.

Through 1993, ERIC citations continued to be by author and title of chapter, with the journal entry giving the volume and issue numbers and the date. However, in 1993, a note was added, giving the sequential numbers. Issues number 84 and number 85 also include the issue title in the Note field. However, this ceased after issue number 85 , winter 1994. The issue number is no longer furnished. Given that most libraries in this sample cataloged the series by sequential number, this omission would make it very difficult for patrons to make the leap from the ERIC index to items owned by libraries.

Education Index. Education Index has cited NDCC from 1983 (number 42) to the present. All of these issues are cited by sequential number only. In addition to indexing the individual articles from each issue, Education Index also cites the entire issue, giving the issue titles and the issue editors. No volume and issue numbering is provided. The format of this index coincides with most of the cataloging practices at the libraries studied.

Carl UnCover. Carl UnCover indexes NDCC back to number 65 , spring 1989 , by sequential number only. Each full record includes author and chapter title, series title, season, year, and sequential number. No issue titles or issue editors are given.

ArticleFirst. ArticleFirst started index- ing NDCC in the summer of 1992. It indexes by chapter author and title, series title, volume number, issue number, and date. The volume number listed varies between arabic numbers and roman numerals. The issue number is actually the sequential number. Thus, ArticleFirst combines the two numbering systems. Sometimes an issue description is included, the description being the unique issue title. However, that field is not searchable by title or keyword. In the fall of 1995, issue number 91 is identified by sequential number only. The volume and issue numbers are absent. With issue number 92 , the unique issue title is omitted.

\section{Citations From Social Sciences CitATION INDEX}

The Social Sciences Citation Index (SSCI) was examined for treatment of this title. The treatments are described below; an outline is provided in table 4 .

An online search through Dialog of SSCI yielded the following results. Seventy-four $(68 \%)$ of the citations listed the issue title, often including the editor of the issue. Ninety-one ( $76 \%$ ) gave the sequential number, while $24(20 \%)$ listed the volume number. Of those citing the volume number, 9 also included the issue number. Five gave no identifying number, only the year. One author gave the sequential number but called it volume 77 (1992). Most used only the numbers and year, not indicating whether it is the volume or the sequential number.

A second online search of SSCI through Dialog was done by author and year for the 5 most cited authors. This 
search produced 17 citations; all were cited by series title and sequential number.

\section{IMPLICATIONS FOR LIBRARIES}

How can finding known items in catalogs that were cited in indexes be made more efficient? What are our options? Though solutions are difficult to implement and may be prohibitively costly, it is productive to discuss possible resolutions. $\mathrm{Be}$ cause the catalog has the greatest impact on access for patrons, it would be productive if the user were kept in mind when records were created and decisions were made about numbered monographic series.

The first implication deals with the design of catalogs and decisions made about treatment of series. It should be an explicit goal of catalogs to provide an easy transition to the catalog from bibliographic indexes in which library titles are indexed.

Reference librarians can help with their knowledge of patron behavior. Because each series title is unique, this knowledge usually comes after the fact when referring to a specific title. When reference librarians see the types of difficulties patrons are experiencing, they should have a way of communicating effectively with catalogers to resolve the difficulties. At this stage, it means enhancing or changing a catalog record. Or it might mean a policy change.

Would access be eased if NDCC were cataloged as a serial or as a monographic series? On the basis of this study, when a series is well known by its series title and when it has a dual numbering system with the sequential number prominent, it should be accessible by series title with the identifying sequential number. If possible, both numbers should appear in the record.

The best choices for cataloging a series are as an analyzed serial or as a monograph in a series. There are advantages and disadvantages to each for the patron. Cataloging NDCC as an analyzed serial would give it a shared call number, and all issues at a library would be shelved together. In addition to the serial record, an individual bibliographic record would exist for each item. However, because some libraries restrict usage of their serials, and many li- braries do not allow serials to be checked out, access would be curtailed. Patrons at OhioLINK libraries could not initiate borrowing of NDCC issues from a terminal using patron-initiated circulation modules. They would have to get a copy of an article through interlibrary loan, which entails time delays.

In some libraries, serial records are in a separate catalog. When libraries catalog a series both as a serial and as a monograph, how is one to know which catalog to search for a particular issue? It would be helpful to have cross-linking between these types of catalogs. The patron has already spent time searching indexes and now may need to decide which title to use, which number to use, and which catalog to access.

When libraries catalog these issues as an unanalyzed serial, searching by unique title is fruitless. However, if a series is cataloged as an analyzed serial, a user can retrieve entries either by unique issue title or by series title if these are indexed fields. If it is cataloged as a monograph in a series and it is indexed in the title field by series, it is again retrievable by either title. When it is not indexed by series, searching by series title is futile. To be helpful to patrons who get citations from indexes or references, numbered monographic series should be indexed by series. However, indexing series and analyzing serials may involve greater initial expense for libraries.

The second implication for cataloging concerns the numbering system. The primary source of citation information, the title page, clearly states the issue number and the date. Catalogers are aware that "some data elements have gradually drifted to locations other than the title page, particularly to the verso of the title leaf where it is now common to find date and edition information" (Hagler and Simmons 1982,85 ), but they add that the title page is still the primary source of this information. Looking beyond the title page for further numbering is time-consuming. Libraries are looking to simplify cataloging, not to create complexity. Titles in numbered monographic series with dual numbering systems where the index- 
ing service uses only the volume and issue numbers create complexity. Access by the series title, with the date and both numbering systems noted in the series field, might facilitate access. This is especially true when the dominant number is the sequential number and most authors are used to citing volume and issue numbers.

Repercussions for interlibrary loan (ILL) loom large. Seaman (1992) explains that ILL requests for books can be generated as a result not only of user error but by catalog failure for items actually owned by the requesting library. One category of catalog failure is that no analyzed entry exists for series titles cataloged as serials. One serial entry for numerous issues of this series is common practice at many of the libraries studied. Seaman dealt with requests for ILL in error that were found by ILL staff and were identified as being owned by the borrowing library.

Two other situations make ILL more elusive. Through OhioLINK all registered users can borrow monographs by requesting them without ILL or staff intervention. This feature is called patroninitiated circulation. If an item is located in the central catalog, any member library user can initiate a request that will then be accepted by the system as valid when the same item is not owned or is unavailable at the user's home library. Where the cataloging treatment is the same, the system can easily make this determination. However, when one library has cataloged a title as a serial and another has it as a monographic series, the system cannot determine the sameness. If a monograph in a series is requested despite the fact that the user's host library owns the serial, the system will allow the request.

The second situation assumes that the staff of ILL can make all the leaps from volume number to sequential number and know that the item is actually owned but is cataloged differently. Can the ILL office interpret all of this information for monographic series with dual numbering systems, given the variety of cataloging apparent at various libraries?

Acquisitions is also affected. When an item is not cataloged in the way it is being requested, libraries might purchase addi- tional copies, thinking they do not own a particular issue. Some libraries in the study have extra copies of various issues of this title. These extra copies might be due to its popularity, or they might be due to mistakenly purchasing a copy when the catalog record for an issue could not be found in preorder searching.

In the public service area, public service librarians must be knowledgeable about these issues to teach patrons to be flexible, to question whether the citation in hand is complete, correct, or needs modification to find whether the item is owned at a particular library. We need to instill in our patrons the willingness to ask questions, to appear foolish in order to save hours of searching futilely. We need to learn about the problems facing serial catalogers and to inform them how patrons search for items.

\section{Conclusions}

Regadless of how many titles in series exist in academic library collections, it would seem that indexing the series entries and adding series entries would entail more work if more series were analyzed and dual numbering schemes were always recorded. However, from the perspective of efficient use of the catalog, this effort would reduce the work of users, many of whom are library staff in acquisitions, ILL, reference, and cataloging services. Reference librarians believe the time and effort would be well worth the value, not only in more accurate and efficient access but also in reduced frustration and greater user satisfaction with the catalog. The sharing of resources is highlighting historic inconsistencies and the lack of national standards. Retrospective conversion has been focused on journals with title changes. Now that many libraries have been able to update these records, it might be time to ease access for series.

A national policy on series cataloging appears to be evolving. In the Cataloging Service Bulletin (Library of Congress, 1996,11 ), it is stated that:

the Library of Congress Rule Interpretations (LCRIs) provide for a common practice, sometimes called 'national' practice. . . 
Moreover, it is incumbent upon the $\mathrm{Li}$ brary of Congress to make decisions to provide common practice in order to share bibliographic and authority records for the common good, which may at times be at odds with local needs. . . . In the case of series, the practice applies to LC and to those NACO libraries that contribute series authority records.

CSB includes LC practice guidelines for tracing analyzed series. LC is taking a leadership role in advancing the practice that series should be traced by series statement. Complying with the common practice is expected to result in more series entries and serial numbering in the catalog, but it will provide more efficient access. The trend to limit the number of access points to speed up the cataloging process may have had the unintended consequence of making it more difficult for patrons to access items from citations taken from electronic indexes. The vast resources of electronic indexes need to be supported by strengthening citation forms in the catalog.

Can librarians influence publishers? Publishers, first and foremost, want to remain in business and remain profitable. Librarians can inform them of difficulties their publishing practices are creating. Perhaps this awareness will open dialogue for greater understanding, even if, for example, it does not change a dual numbering system for a currently published journal. In addition, some journals include recommended forms for citation with the articles in each issue. Making this practice a model and integrating it with cataloging practices would bring clarity where there was confusion.

To standardize a catalog to agree with citation indexes would be impossible given the lack of standardization of these services. However, as more library catalogs link citation indexes to their bibliographic records, it would appear that a solution must be found for this linkage to succeed. Effort may need to be placed on system solutions to integrate index citations with the library's catalog. As more companies seek solutions to these issues, it seems feasible that an algorithm will be developed to link the index citations to the correct entry in the library catalog. Having consistent and enhanced access points for series entries would make linking catalogs with similar access points in indexes useful and productive. Having standards for series entries that are followed by publishers and libraries and that incorporate additional access points that are possible with electronic catalogs could make the link from citation to piece in hand a quick and efficient process for patrons and librarians alike.

\section{WoRKs CITED}

Crawford, Walt. 1987. Patron access: Issues for online catalogs. Boston: G. K. Hall.

_. 1992. The online catalog book: Essays and examples. New York; G. K. Hall.

Hagler, Ronald, and Peter Simmons. 1982. The bibliographic record and information technology. Chicago: ALA.

Intner, Sheila S. 1990. Access to serials-part 1: A look at the bibliographic unit. Technicalities 10 (Jan.): 3-5.

Library of Congress. 1996. Cataloging service bulletin, 74 (Fall).

McBride, Ruth B. 1985. Analysis of monographic series. In Libraries in the ' 80 s: Papers in honor of the late Neal L. Edgar, ed. Dean H. Keller. New York: Haworth.

New directions for community colleges. 1974. no. 5.

Seaman, Scott. 1992. Online catalog failure as reflected through interlibrary loan error requests. College \& research libraries 53 : 113-20.

Snavely, Loanne, and Katie Clark. 1996. What users really think: How they see and find serials in the arts and sciences. Library resources i technical services 40: 49-60.

Steinhagen, Elizabeth N. 1989. Monographic series in a network environment. The serials librarian 16: 65-74.

Tagliacozzo, Renata, Lawrence Rosenberg, and Manfred Kochen. 1970. Access and recognition: From users' data to catalogue entries. Journal of documentation 26: 230-49.

Tate, Elizabeth L. 1963. Main entries and citations: One test of the revised cataloging code. Library quarterly 33: 172-91.

Tyckoson, David. 1989. The $98 \%$ solution: The failure of the catalog and the role of electronic databases. Technicalities 9 (Feb.): 8-12. 